\title{
308 MR guidance and monitoring of intramyocardial delivery of VEGF Gene in coronary artery occlusion in canine model
}

\author{
Maythem Saeed*, Alastair J Martin, Loi Do, Alexis Jacquier, Charles B Higgins \\ and David Saloner
}

Address: University of California San Francisco, San Francisco, CA, USA

* Corresponding author

from I th $^{\text {th }}$ Annual SCMR Scientific Sessions

Los Angeles, CA, USA. I-3 February 2008

Published: 22 October 2008

Journal of Cardiovascular Magnetic Resonance 2008, IO(SuppI I):AIII doi:I0.I I86/I532-429X-I0-SI-AIII I

This abstract is available from: http://jcmr-online.com/content/I0/SI/AIII

(c) 2008 Saeed et al; licensee BioMed Central Ltd.

\section{Introduction}

Ischemic cardiomyopathy resulting from LV remodeling and conversion of myocytes to scar tissue is the eventual scenario in severe coronary disease. A candidate treatment for this condition is therapeutic angiogenesis. A percutaneous transendocardial approach to therapeutic angiogenesis in ischemic myocardium aims to: 1) achieve locally effective concentration of therapy; 2) minimize side-effects associated with systemic distribution; 3 ) minimize the effect of blood enzymes on genes and 4) eliminate open-chest surgery and extended hospitalization.

\section{Purpose}

To: 1) explore the effectiveness of MR-fluoroscopy for targeted delivery of genes in occlusive infarction; and 2) evaluate VEGF gene effect on MR measurements of perfusion, infarction size and LV function.

\section{Methods}

Three days after coronary artery occlusion, the infarction was visualized as a bright region on delayed contrast enhanced MRI (CE-MRI) (Figure 1) and used as a target for delivering therapy. MR fluoroscopy was used for guiding the endovascular catheter and gene delivery. The delivery required 1) the catheter's tip is perpendicular to desired injection site, 2) ectopic extraventricular beats appeared at needle penetration of LV and 3) injection of Dy-DTPA-BMA into sample locations of myocardium. VEGF $(n=6)$ or LacZ gene $(n=6)$ was injected into the border and core of CE-MR region.

\section{Results}

The signal derived from the active catheter allowed simultaneous visualization of the catheter and vascular wall (Figure 1). MR Measurements. Treated, but not control, animals showed improved LV function as shown by increased ejection fraction and decreased LV end systolic volume at 7-8 wks (Figure 2). At 7-8 wks, signal intensity of infarcted myocardium in treated animals increased by $158 \%$ compared with $79 \%$ controls on first-pass perfusion imaging. Both groups showed a significant decrease in the extent of contrast enhanced regions as compared with 3 days. VEGF gene caused a $9.4 \%$ greater reduction in the extent of the enhanced region than controls. The extent of Gd-DOTA-enhanced region was $8.5 \pm$ $0.9 \%$ in treated and $11.3 \pm 0.9 \%$ in controls $(P=0.03)$ and comparable to TTC.

\section{Histopathology}

At 7-8 wks infarcts were characterized by the presence of scar tissue. Infarcts from treated and control hearts contained a few scattered thick-walled arteries as demonstrated by Masson's trichrome stain. Infarcts from treated animals showed numerous small caliber thin-walled vessels in the scar tissue. Biotinylated isolectin B4 delineated vascular endothelial cells with brown reaction product (Figure 3). Infarcts from VEGF gene treated showed a haphazard distribution of numerous vessels within the scar. 


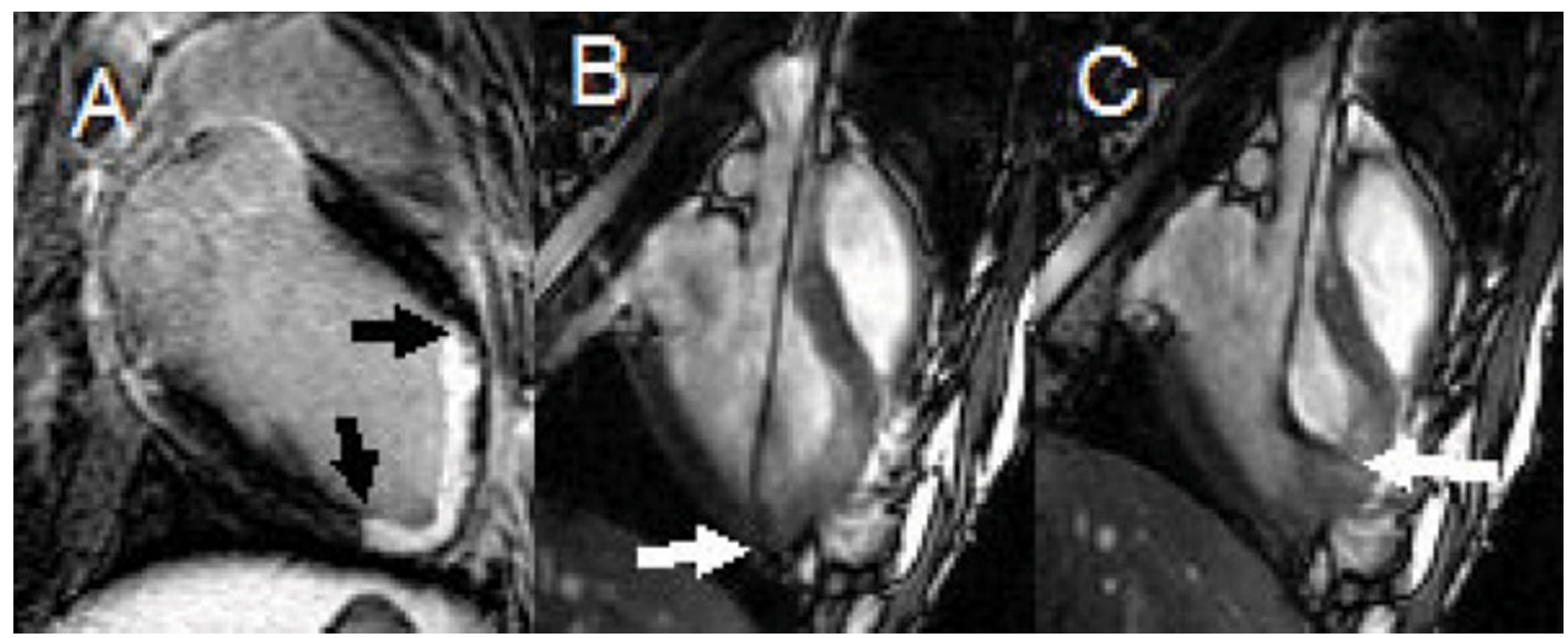

Figure I

CE-MR image (A) shows hyperenhanced infarcted myocardium as a target for delivering therapy (arrows). Real time images (B, C) show the endovascular catheter in LV (arrows).

\section{Conclusion}

MR-guided transendocardial delivery of genes into occlusive infarction is an effective technique for revascularization. This new delivery approach resulted in improved global LV function and prevented LV remodeling that otherwise was noted to occur in control animals at 7-8 weeks after occlusion. The effectiveness of this approach most likely stems from the effect of VEGF in promoting new blood vessels in the target.
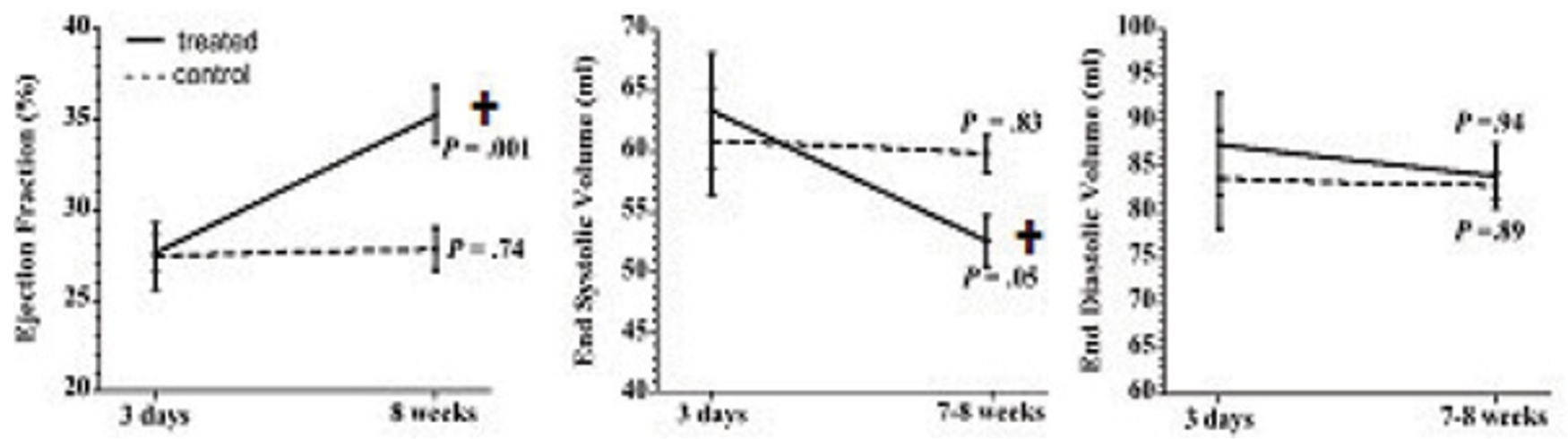

\section{Figure 2}

Changes in ejection fraction (EF) (left), end systolic (middle) and end diastolic (right) volumes after coronary occlusion in control and treated animals. VEGF gene increased the EF and decreased end systolic volume. Bold = treated; Dashed $=$ control. 

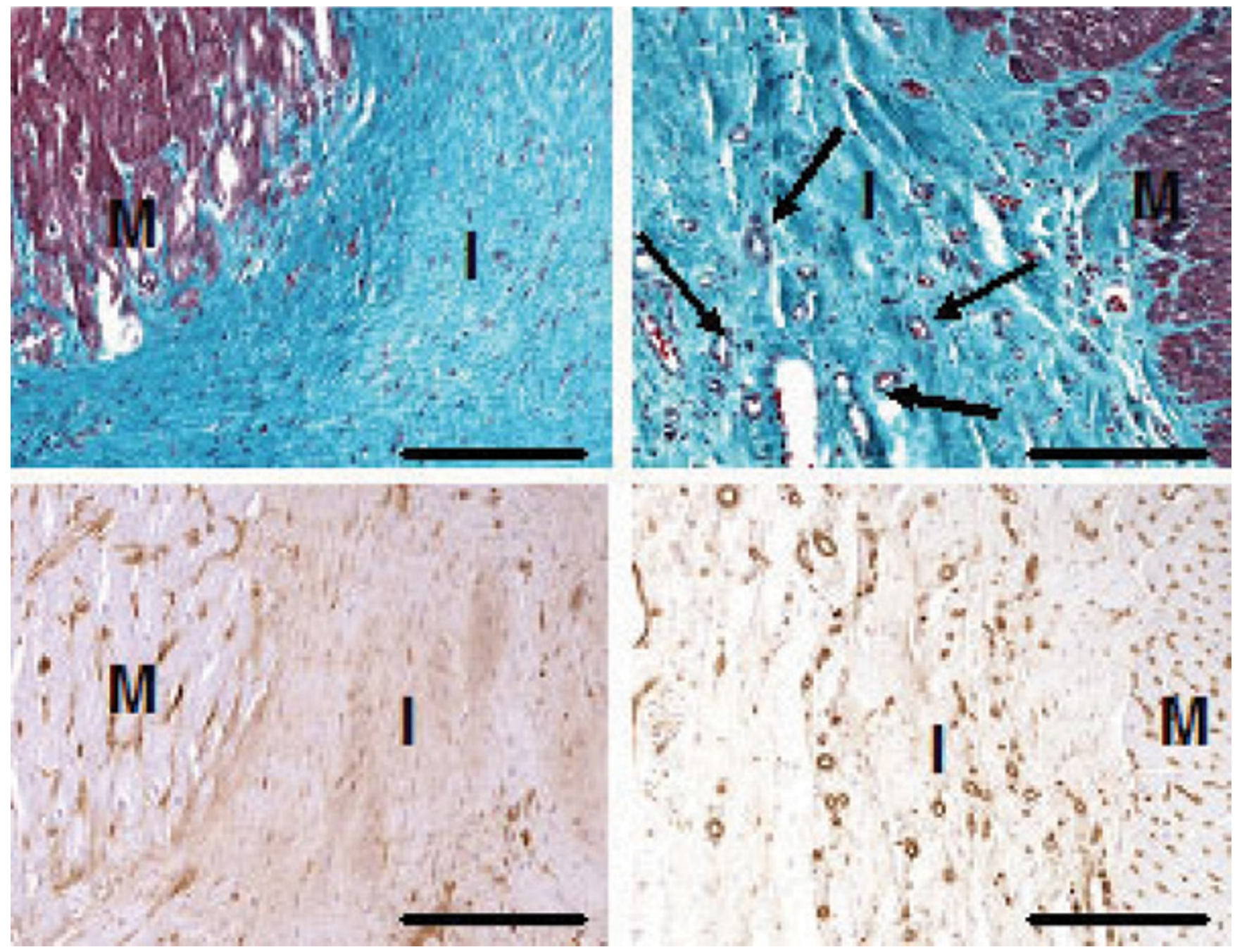

Figure 3

Histology of control (left) and treated (right) infarcts (I). The healed infarct in treated animals contained numerous blood vessels (arrows), while a comparable area from control infarcts contained very few blood vessels. Isolectin B4 localized blood vessels accentuates neovascularity of treated infarcts, as compared with control. Top panels stained with Masson trichrome and bottom panels with isolectin B4. Calibration bars $=80 \mu$.

Publish with Bio Med Central and every scientist can read your work free of charge

"BioMed Central will be the most significant development for disseminating the results of biomedical research in our lifetime. " Sir Paul Nurse, Cancer Research UK

Your research papers will be:

- available free of charge to the entire biomedical community

- peer reviewed and published immediately upon acceptance

- cited in PubMed and archived on PubMed Central

- yours - you keep the copyright 